\title{
Complexidade, Formalismo Teórico e Liberdade
}

\author{
Fabio Barbieri*
}

\begin{abstract}
Resumo: Este artigo discute o 'dilema lachmaniano': uma teoria sobre ordens espontâneas requer os elementos de subjetivismo metodológico e complexidade do problema alocativo, mas a representação formal na teoria econômica da complexidade do problema econômico traz consigo o risco de perdermos de vista a própria apreciação desses elementos. Uma saída para esse dilema é dada por uma interpretação metodológica adequada dos conceitos teóricos. Nesse sentido, argumentaremos que os austríacos são seguidores da metodologia clássica no que diz respeito às consequências da complexidade.
\end{abstract}

Palavras-Chave: Complexidade. Subjetivismo. Formalismo.

\section{Complexity, Theoretical Formalism and Liberty}

\begin{abstract}
This article discusses the 'Lachmannian dilemma': a theory about spontaneous orders requires methodological subjectivism and the complexity of the allocative problem. However, the formal representation of the economic problem in the economic theory of complexity carries the risk of losing sight of the very appreciation of those elements. A way of overcoming the dilemma is given by an appropriate methodological interpretation of the theoretical concepts. In this sense, we argue that the Austrians are the followers of the classical methodology concerning que consequences of complexity.
\end{abstract}

Keywords: Complexity. Subjectivism. Formalism.

Classificação JEL: B41, B53.

\footnotetext{
"Fabio Barbieri é mestre e doutor pela Universidade de São Paulo. Autor dos livros "A Economia do Intervencionismo" e "História do Debate do Cálculo Econômico Socialista". Atualmente, é professor da USP na FEA de Ribeirão Preto. E-mail: barbieri@mises.org.br
} 


\section{I - INTRODUÇÃO: COMPLEXIDADE E SUBJETIVISMO COMO ELEMENTOS CRUCIAIS DE UMA TEORIA ECONÔMICA LIBERAL}

A defesa da liberdade baseada em argumentos econômicos requer tanto a crítica aos mecanismos centralizados de escolha quanto a demonstração da superioridade dos arranjos institucionais compatíveis com a interação descentralizada. A coordenação das ações individuais sob a ordem espontânea dos mercados, deve-se mostrar, possibilita contínuos ganhos de produtividade advindos da especialização que não podem ser mantidos sob arranjos institucionais centralizadores. Estes sofreriam invariavelmente dos problemas gerados pelas consequências não intencionais dos planos, contrárias aos intentos dos planejadores centrais.

Quais seriam então os elementos fundamentais de uma teoria econômica que propõe a tese exposta acima? O exame da história do pensamento econômico nos revela dois ingredientes básicos, que podem ser identificados pelos rótulos "complexidade" e "subjetivismo". Os economistas que valorizam os mercados tendem a salientar a complexidade do problema econômico e as maneiras como essa complexidade se relaciona com o conhecimento e os planos de ação de cada agente.

Embora mais evidentes nas obras dos austríacos, complexidade e subjetivismo têm papel preponderante no pensamento liberal em geral, tendendo por outro lado a sair de cena nas teorias daqueles autores que advogam alguma forma de coletivismo. A preocupação com a complexidade das relações sociais e com as motivações dos agentes surge com toda a força, por exemplo, na conhecida metáfora smithiana ${ }^{1}$ que compara a postura do planejador central com a do enxadrista: o planejador erroneamente acredita que as peças do "grande tabuleiro da sociedade hu-

${ }^{1}$ SMITH, A. The Theory of Moral Sentiments. London: H. Bohn, 1853. p. 342. mana" poderiam ser facilmente manipuladas, como as do jogo de xadrez.

A complexidade e o subjetivismo perdem importância, porém, com a formulação do sistema ricardiano. No modelo de crescimento de Ricardo, a ação individual e a complexidade das inter-relações microeconômicas submergem diante da necessidade de manter o foco nas relações entre agregados macroeconômicos, até desaparecerem quase por completo com o surgimento da macroeconomia keynesiana. Tendo diante de si apenas variáveis agregadas, o condutor da política econômica se sente à vontade no papel do enxadrista smithiano.

$\mathrm{Na}$ crítica misesiana ${ }^{2}$ ao socialismo, por outro lado, subjetivismo e complexidade são centrais. No artigo de Mises, a ênfase na complexidade do problema alocativo se manifesta através do elemento temporal presente na teoria austríaca do capital: existem ao longo do tempo infinitas combinações técnicas possíveis entre fatores primários e bens de capital existentes e a única maneira de navegar nesse mar de possibilidades é o uso da bússola provida pelos preços:

Somente devido ao fato de que as considerações técnicas podem ser baseadas em lucratividade podemos superar a dificuldade que decorre da complexidade das relações entre o poderoso sistema atual de produção, por um lado, e a demanda e eficiência das empresas e das unidades econômicas, por outro lado ${ }^{3}$.

O subjetivismo também é central na análise do autor, pois as escolhas entre as infinitas possibilidades técnicas só fazem sentido em termos dos fins buscados por cada agente. Complexidade e subjetivismo não apenas se fazem presentes, como também interagem. A complexidade colocada pelas múltiplas esco-

${ }^{2}$ MISES, L. Economic Calculation in a Socialist Commonwealth. In: HAYEK, F.A. (Ed.). Collectivist Economic Planning. London: Routledge, 1935 [1920].

${ }^{3}$ Idem. Ibidem, p. 129. 
lhas técnicas possíveis nos leva a considerar as limitações do conhecimento do agente sobre essas possibilidades, de modo que o sistema de preços possibilita "uma espécie de divisão intelectual do trabalho" ${ }^{4}$.

Friedrich A. Hayek (1899-1992)5, inspirado por sua contribuição ao mesmo debate sobre o cálculo econômico socialista, acrescenta que o subjetivismo não basta para uma explicação satisfatória a respeito da emergência da coordenação nos mercados: além da consistência interna entre meios e fins de um plano subjetivo, devemos explicar porque os diferentes planos individuais são compatíveis entre si, pois cada um contém conhecimento falível, potencialmente errôneo, já que pode desconsiderar consequências relevantes dos planos dos demais.

Isso nos convida a tratar o problema econômico da coordenação por meio de uma teoria de aprendizado: sob que condições o conhecimento falível de cada agente converge, na ausência de novas mudanças exógenas, para teorias empresariais mais próximas dos reais fundamentos da economia (preferências, tecnologias e disponibilidade de recursos)? Uma epistemologia evolucionária ${ }^{6}$, que supõe aprendizado por tentativas e erros, além de privilegiar o elemento subjetivo inerente a uma teoria de aprendizado, implica na complexidade do problema enfrentado pelos agentes, o que torna plausível o emprego da hipótese de conhecimento falível dos agentes. Essa teoria inclui tanto a diversidade proporcionada pela liberdade para tentar soluções rivais para os problemas dos agentes, quanto um mecanismo de correção de erros fornecido pelo sistema de preços.

\section{Idem. Ibidem, p. 102.}

${ }^{5}$ HAYEK, F. A. Economics and Knowledge. Economica, Vol. 4, No. 13, 1937.

${ }^{6}$ BARTLEY III, W. W. \& RADNITZKY, G. Evolutionary Epistemology, Rationality and the Sociology of Science. La Salle: Open Court, 1987.
Neste artigo argumentaremos que a representação formal na teoria econômica da complexidade do problema econômico traz consigo o risco de perdermos de vista a própria apreciação dos elementos de complexidade e subjetivismo. Apesar do risco, uma teoria sobre ordens espontâneas requer tal representação. Uma saída para esse dilema é dada pela correta interpretação metodológica dos conceitos teóricos. Nesse sentido, argumentaremos que os austríacos são seguidores da metodologia clássica no que diz respeito à importância que a complexidade desempenha nessa tradição metodológica.

\section{II - Um Dilema Metodológico: o FORMALISMO "RICARDIANIZA" A TEORIA}

A emergência da ordem espontânea dos mercados requer teorias que contemplem tanto o elemento subjetivo da criação e descoberta empresarial quanto a representação das restrições exteriores impostas à vontade dos agentes. A partir da combinação desses dois elementos em uma teoria da competição sob descentralização, pode-se explicar a superação da complexidade inerente ao problema da coordenação das ações individuais.

Essas restrições são representadas por simplificações teóricas que, por definição, deixam de lado diversos aspectos do objeto estudado. A estrutura do capital entre autores austríacos é representada por processos de input contínuo - output pontual, abstraindo as inúmeras formas pelas quais os bens de capital podem ser combinados ao longo do tempo. Na microeconomia os ordenamentos de preferência dos agentes são representados por funções utilidade e as restrições técnicas em cada setor da economia por funções de produção e suas propriedades, como rendimentos decrescentes. Nas duas funções, ignora-se, entre outras coisas, o elemento temporal presente nas escolhas de consumo e produção. 
Essas simplificações, porém, nos levam a um dilema metodológico. Desenhadas para ilustrar como o planejamento descentralizado é capaz de contornar as limitações do conhecimento subjetivo diante da complexidade do problema alocativo de maneira que o planejamento central não é capaz, a representação teórica simplificada das restrições, se interpretadas literalmente, pode gerar efeito oposto, sugerindo impressão de simplicidade e capacidade de gestão centralizada.

Esse perigo faz parte das preocupações metodológicas dos austríacos. Hayek ${ }^{7}$ salienta o problema quando aponta a confusão moderna entre o conhecimento abstrato do analista e o cambiante conhecimento particular dos agentes, confusão essa que possibilita a crença na capacidade de intervenção governamental exitosa nos mercados.

Ludwig Lachmann (1906-1990)', por sua vez, mostra que o problema é especialmente relevante diante da moderna valorização do formalismo teórico. Esse autor define formalismo não como o uso da matemática na teoria econômica, mas como o uso de ferramenta analítica fora do seu contexto original, ignorando suas limitações. Embora simplificações drásticas sejam necessárias para a formulação de modelos formais tratáveis, o economista tende a transferir a simplicidade do modelo para a realidade. Isso faz com que os elementos de complexidade e subjetividade sejam perdidos de vista.

Lachmann ilustra essa tese com o desenvolvimento do que denomina "contrarrevolução ricardiana" na macroeconomia na metade do século passado. Para o autor, o apego formal à noção de equilíbrio permite que se trabalhe com conceitos agregados que não são

${ }^{7}$ HAYEK, F. A. The Use of Knowledge in Society. The American Economic Review, Vol. 35, No. 4., 1945. Parte 3.

8 LACHMANN, L. Macroeconomic Thinking and the Market Economy: An Essay on the Neglect of the Micro-foundations and Its Consequences. London: Institute of Economic Affairs, 1973. p.8. microfundamentados na ação proposital dos indivíduos. Assim, estruturas complexas dão lugar a agregados uniformes e considerações subjetivas, como as expectativas, desaparecem.

No debate sobre o cálculo socialista, do mesmo modo, o formalismo do modelo de equilíbrio geral induziu os socialistas de mercado ao erro de transferir a simplicidade da teoria para o mundo real. Em equilíbrio, ignoram-se os processos pelos quais os agentes conjecturam sobre as mudanças contínuas nos fundamentos da economia e essas conjecturas são corrigidas. Nesse ambiente, independentemente de pressões competitivas e instituições, as firmas de algum modo conhecem de início as estáveis funções de produção de seu setor e os custos de oportunidade dos recursos são assim facilmente identificáveis. Os agentes precisam apenas ocasionalmente reagir de forma paramétrica a preços ditados centralmente.

Mas, quando constroem suas próprias teorias, os austríacos também empregam simplificações. Carl Menger (1840-1921) fala em "necessidades reais", independentes do julgamento individual. Eugen von Böhm-Bawerk (1851-1914) adota simplificação drástica em sua representação da estrutura do capital, utilizando o problemático conceito de "período médio de produção" e Hayek emprega simples triângulos para representar a mesma estrutura na teoria austríaca dos ciclos. Mas, independentemente da utilidade e das limitações dessas simplificações teóricas, esses autores nunca perderam de vista a complexidade do objeto estudado.

Como é possível então evitar as armadilhas do que poderíamos denominar dilema lachmanniano? A representação formal das restrições às vontades humanas carrega consigo o perigo de "ricardianização" (transferência da simplicidade da teoria para a realidade), mas por outro lado o refúgio no subjetivismo radical impede o desenvolvimento de uma teoria sobre ordens espontâneas, na medida em que teríamos presente apenas o elemento 
subjetivo de racionalidade, mas não a descrição de mecanismos de adaptação dos planos subjetivos aos obstáculos impostos pelo mundo exterior.

Esse dilema é especialmente significativo para o desenvolvimento futuro da escola austríaca se essa se propuser ir além da esfera das verdades genéricas de natureza puramente praxiológica. O desenvolvimento dessa escola requer avanços no desenvolvimento da teoria pura de auto-organização, na teoria aplicada sobre as consequências econômicas de arranjos institucionais diferentes ou ainda na aplicação histórica da teoria pura. Em todos esses campos é necessário o uso de hipóteses com grau menor de generalidade.

A solução do dilema acima exposto requer o exame da postura metodológica austríaca no que diz respeito à complexidade. Afinal, apesar da adoção de simplificações teóricas, os autores austríacos tiveram sucesso em contornar a armadilha. Na próxima seção, examinaremos a evolução da metodologia da economia para argumentar que os austríacos são herdeiros do pensamento clássico no que diz respeito às consequências metodológicas da complexidade.

\section{III - A Evolução do Pensamento MetodolóGico: A MATemática SEM NÚMEROS}

O processo de transferência da simplicidade dos modelos teóricos para o objeto estudado tem entre suas causas a evolução do pensamento metodológico. Na evolução da Metodologia da Economia, podemos postular uma divisão em três períodos. Essa periodização é obtida pela sobreposição de dois eventos revolucionários na disciplina.

O primeiro foi a Revolução Marginalista de 1971. Além da substituição de uma teoria do valor objetiva por outra subjetiva e do em- prego do marginalismo, podemos constatar que metodologicamente ocorreu uma mudança significativa, caracterizada pela defesa do emprego da matemática como modo de expressão. Com exceção de Menger, os primeiros marginalistas dedicaram parcelas significativas da introdução, primeiros capítulos ou apêndices de suas obras para defender a linguagem matemática como veículo apropriado para a discussão científica em Economia. Com o sucesso desse discurso, podemos dividir a história da Economia em duas fases: na primeira, anterior a 1871, predominava o emprego de argumentação verbal, prática desprezada como "economia literária" pelos proponentes da Revolução Formalista que iniciaram a segunda fase. Estes últimos acreditavam que o formalismo traria maior clareza e precisão ao argumento teórico.

O segundo evento foi a Revolução Empirista da década de 1930, que marca o abandono de uma perspectiva apriorista por um programa metodológico que demanda hipóteses econômicas econometricamente testáveis.

A sobreposição dessas duas revoluções gera nossa classificação em três períodos, representados na figura 1 . No primeiro período, marcado pelo tratado metodológico de John Stuart Mill (1806-1873), temos a Economia verbal apriorista. No segundo, representado pelo tratado de John Neville Keynes (18511949), predomina a abordagem formalizada, mas ainda apriorista. No terceiro, caracterizado pelo artigo de Friedman, o empirismo se junta ao formalismo?.

${ }^{9}$ MILL. J. S. On the Definition of Political Economy; and on the Method of Investigation Proper to It. In: MILL, John Stuart. Essays on Some Unsettled Questions of Political Economy. Kitchener: Batoche Books, 2000 [1844]; MILL, J. S. A System of Logic. New York: Harper \& Brothers, 1882. Ebook: Gutteberg Project, 2009; KEYNES, J. N. The Scope and Method of Political Economy. Kitchener: Batoche Books, 1999 [1890]; e FRIEDMAN, M. The Methodology of Positive Economics. In: Essays in Positive Economics. Chicago: Univ. of Chicago Press, 1966. 


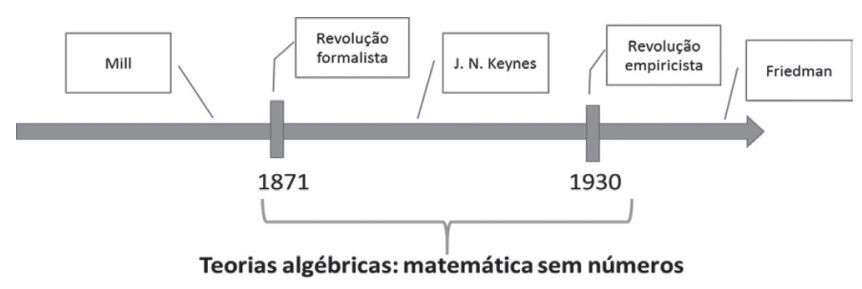

Vejamos ao longo dessa evolução como a metodologia se relaciona com a complexidade do fenômeno econômico. Os economistas clássicos britânicos ${ }^{10}$, embora inclinados ao empirismo nas ciências naturais, defendiam a tese da dualidade do método, caracterizando a Economia como disciplina dedutiva. Além de tratar de hipóteses subjetivas (psicológicas, segundo o termo da época), a complexidade dos assuntos econômicos estava no centro do argumento. Quando muitos fatores influenciam uma grandeza ou parte delas de natureza subjetiva e, portanto, não observável, ou ainda outra parte não se prestando ao controle do cientista, não é possível discernir leis derivadas empiricamente, argumenta Mill em seu ensaio metodológico. Em seu lugar, devem-se utilizar hipóteses básicas derivadas de observações e introspecção e destas derivam-se leis de tendência que não podem ser verificadas, pois é impossível asseverar se os demais fatores atuantes sobre o fenômeno não se alteraram simultaneamente.

Nessas circunstâncias Mill ${ }^{11}$ se posiciona contrário ao uso da matemática, pois não se podem determinar valores numéricos quando temos causas não observáveis, muitas causas interdependentes atuando simultaneamente e quando as mesmas mudam continuamente. Assim, podemos inferir que para Mill o uso de equações implica na crença de que a complexidade das situações reais seria dissolvida em sua representação simbólica.

\footnotetext{
${ }^{10}$ SENIOR, N. W. An Outline of the Science of Political Economy. New York: Augustus M. Kelley, 1965 [1836]; MILL. Essays on Some Unsettled Questions of Political Economy; e CAIRNES, J. E. The Character and Logical Method of Political Economy. Kitchner: Batoche Books, 2001 [1888].

${ }^{11}$ MILL. A System of Logic, parte 5, p. 761.
}

Essa crença é explicitamente rejeitada no segundo período. Para os autores desse período, o uso da matemática não implica em absoluto mensuração, como argumentou J. N. Keynes $^{12}$. Antoine Augustin Cournot (1801$1877)^{13}$, por exemplo, sabe que não é possível estimar curvas de demanda, pelos mesmos motivos apontados por Mill, mas ainda assim estas seriam imprescindíveis para o desenvolvimento da teoria de monopólio e oligopólio. As equações deveriam ser interpretadas como no primeiro período: como relações abstratas entre variáveis, como se outros fatores não atuassem simultaneamente e os dados não se alterassem a cada instante. No mesmo espírito, Edgeworth ${ }^{14}$ dá o título de "matemática sem números" à parte teórica de seu tratado.

Embora nesse período já esteja latente o risco do analista acreditar que o mundo seja tão simples como seus modelos, é no terceiro período que tal fenômeno se manifesta. Nele, o uso da economia matemática como uma espécie de geometria é rejeitado em favor de modelos potencialmente testáveis. Karl Gustav Cassel (1866-1945) ${ }^{15}$ foi um dos primeiros autores a exprimir a opinião de que a matemática só teria valor se fizesse referência a grandezas mensuráveis.

O debate do cálculo econômico socialista ilustra de maneira mais completa o fenômeno de ricardianização inerente à teoria formal: o aparato outrora utilizado para explicar alguns aspectos do funcionamento do sistema de preços passa a ser visto como suficiente para fornecer um substituto artificial desse sistema. Os diversos elementos do fenômeno

${ }^{12}$ KEYNES. The Scope and Method of Political Economy.

${ }^{13}$ COURNOT, A. Researches into the Mathematical Principles of the Theory of Wealth. London: MacMillian, 1897 [1838]. p. 47.

${ }^{14}$ EDGEWORTH, F. Y. Mathematical Psychics: An Essay on the Application of Mathematics to the Moral Sciences. London: C Kegan Paul, 1881.

${ }^{15}$ CASSEL, G. On Quantitative Thinking in Economics. London: Oxford University Press, 1935. 
real da competição, que ficaram de fora de sua descrição teórica, subitamente se tornam descartáveis, ilustrando assim o defeito inerente àquilo que Lachmann denomina formalismo.

\section{IV - Metodologia Austríaca: A HERANÇA CLÁSSICA}

A metodologia clássica, com sua peculiar consciência das limitações da teoria em capturar as complexidades do mundo real, embora tenha entrado em declínio com o advento do positivismo, ainda foi influente no século passado. Mesmo John Maynard Keynes (1883-1946) ${ }^{16}$, talvez influenciado pelo tratado de seu pai, afirma que " é da essência de um modelo que não se preencha as variáveis com valores reais. Fazê-lo o tornaria inútil como modelo", já que o mesmo perderia sua generalidade.

Os principais herdeiros modernos do pensamento metodológico clássico, porém, foram os austríacos. Embora estes sejam comumente vistos como hostis ao classicismo, devido à rejeição da teoria objetiva do valor e do conceito clássico de Homo economicus, os escritos metodológicos austríacos seguem linhas clássicas, em particular no que diz respeito à postura diante da complexidade do fenômeno econômico.

Menger ${ }^{17}$, em sua crítica ao historicismo alemão, acusa seus oponentes de não distinguir as diferentes orientações de pesquisa econômica. O ramo exato da orientação teórica é descrita pelo autor em termos idênticos aqueles expostos pela metodologia clássica:

\footnotetext{
${ }^{16}$ KEYNES, J. M. Economic Model Construction and Econometrics. In: HAUSMAN, Daniel M. (Ed.). The Philosophy of Economics: An Anthology. Cambridge: Cambridge University Press, 1994.

${ }^{17}$ MENGER, C. Investigations into the Method of the Social Sciences. Grove City: Libertarian Press, 1996 [1882].
}

parte-se do isolamento de uma causa particular (tipos exatos), como por exemplo o comportamento aquisitivo (Homo economicus), a partir da qual são deduzidas consequências verdadeiras (leis exatas), admitindo-se que apenas essa única causa operasse, sendo a história capaz apenas de ilustrar a aplicabilidade do fator isolado. O ramo empírico-realista, por sua vez, devido à complexidade do objeto estudado, seria capaz apenas de gerar leis de tendência, como em Mill.

Ludwig von Mises (1881-1973) ${ }^{18}$, embora substitua a hipótese particular de Homo economicus pelo axioma geral da ação, também segue o roteiro clássico, enfatizando a complexidade como empecilho ao método empírico: para ele não existiriam constantes como as da Física no que diz respeito aos fenômenos sociais. Como os clássicos, Mises salienta a impossibilidade de experimentos controlados, defende teoria dedutiva, válida a priori e os exemplos históricos apenas ilustram a aplicabilidade dos axiomas.

Hayek $^{19}$, por sua turno, coloca a complexidade no centro de suas preocupações metodológicas. Quanto mais complexo o fenômeno estudado, ou seja, quanto maior o número mínimo de variáveis necessárias para uma explicação aceitável de um fenômeno, menor o conteúdo empírico de uma teoria. O estudo de fenômenos complexos deveria então usar teorias abstratas que se limitam a previsões de padrões gerais e não de detalhes das manifestações específicas do padrão estudado.

Desimpedidos pela exigência de tratabilidade imposta pelo formalismo matemático, os austríacos não se acanharam em usar explicações não operacionalizáveis empiricamente quando a complexidade do fenômeno estudado assim o exigia. Se índices de preços não forem adequados para a explicação dos ciclos

${ }^{18}$ MISES. Economic Calculation in a Socialist Commonwealth.

${ }^{19}$ HAYEK, F. A. The Theory of Complex Phenomena. In: HAYEK, F. A. Studies in Philosophy, Politics and Economics. London: Routledge, 1967. p. 22-42. 
econômicos, os austríacos não se sentiram impedidos de empregar alterações na estrutura de preços relativos em suas explicações.

\section{V - Conclusão}

As teses expostas e defendidas neste artigo podem ser resumidas pelas seguintes proposições:

A defesa econômica da liberdade requer salientar os elementos centrais de complexidade e subjetivismo.

Subjetivismo não é suficiente: complexidade surge como representação de obstáculos aos desejos.
Dilema de Lachmann: a representação formal dos obstáculos tende a reduzir a percepção dos economistas sobre os elementos de complexidade e subjetivismo.

Solução do dilema: interpretar metodologicamente relações formais como explicações de padrões abstratos e não como ferramentas de previsões.

Evolução da metodologia: formalismo e empirismo sucessivamente levaram ao abandono da solução citada acima.

Conclusão: deve-se buscar sofisticação metodológica, tal como expressa na metodologia clássica, para que se construa uma teoria econômica que valorize soluções descentralizadas para o problema alocativo, enfatizando-se os elementos de complexidade e subjetivismo. cos 